\title{
Towards integrated devices for ultra-fast all-optical signal processing in optical networks
}

\author{
Ivan Glesk*a ${ }^{*}$ Md Shakil Ahmed ${ }^{\mathrm{a}}$, Zifei Wang ${ }^{\mathrm{b}}$ and Lawrence R. Chen ${ }^{\mathrm{b}}$

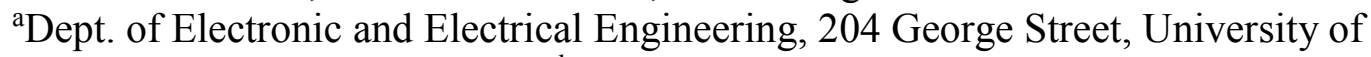 \\ Strathclyde, Glasgow, Scotland, UK; ${ }^{b}$ Dept. of Electrical and Computer Engineering, 3480 \\ University Street, McGill University, Montreal, QC, Canada
}

\begin{abstract}
Over the last decades, the internet traffic has been rapidly growing resulting in Terabits per second aggregate data throughputs. We have also been witnessing that the electronic signal processing the way it is known today is approaching its limitations due to a grooving manifestation of the electronic bottleneck. It is believed that the ultra-fast signal processing based on all-optical integrated devices (passive, active or both) could play an important role in communication systems of the future. In this paper we discuss integrated devices, approaches and techniques we have developed and demonstrated towards achieving these ambitious goals and leading also to improve the scalability of optical networks such as Optical Code Division Multiple Access (OCDMA), namely: all-optical ultrafast demultiplexers, self-clocked all-optical time gates, all-optical thresholders, filters, AWGs, tunable optical delay lines, and devices for dispersion management.
\end{abstract}

Keywords: Scalability, integrated Mach-Zehnder switch, integrated Sagnac switch, subwavelength waveguide grating, integrated optical filters, integrated true delay lines, ultra-fast all-optical signal processing, silicon photonics.

\section{INTRODUCTION}

The increasing demand for high-throughput high-data rates communication is pushing researchers to look for novel devices and highly scalable network architectures. Various multiplexing techniques have been explored. To further increase the network scalability, approaches such as Dense Wavelength Division Multiplexing (DWDM), Optical Code Division Multiple Access (OCDMA) over Time Division Multiplexing (TDM) [1] and hybrid 'WDM and TDM' [2] have been proposed.

Lot of attention has been paid to Optical CDMA systems which can support bursty traffic and carry variable data rates. In particular, OCDMA schemes using Two-Dimensional Wavelength-Hopping Time-Spreading codes (2D-WH/TS OCDMA) were found to be highly flexible multiplexing systems designed for very efficient and scalable multiple access applications. Additionally, 2D-WH/TS OCDMA can offer increased physical layer privacy and on-demand bandwidth sharing management [3].

To further improve the scalability, by deploying 2D-WH/TS OCDMA while allowing the codes reuse, 'OCDMA over OTDM' architecture was proposed and demonstrated [4]. It was shown that the scalability (the total number of simultaneous users) of this hybrid approach is increased by a factor of $M \times N$, where $N$ is the number of used OTDM channels and $M$ is the number of OCDMA users per the OTDM channel. Basing on this concept, the further increase in scalability was demonstrated by adding a third dimension in the spectral domain. This allowed to increase OCDMA user groups operating in each OTDMA time slot by assigning them into $P$ different spectral sub-bands [5]. It was shown that this scaled-up the number of simultaneous user in proportion to the number of spectral bands, leading to a total number of simultaneous users, $k=P \times M \times N$. However, to be able to achieve all the above, all-optical signal processing devices are required. It will be shown that silicon photonics is an excellent platform for underpinning all-optical devices capable of delivering the ultra-fast operation thus need support for these highly scalable OCDMA systems. Desired devices could be fabricated using existing advanced CMOS technology and their future development can be geared towards the highly advanced all-optical integrated solutions. The key advantage of these devices to be used for signal processing should be their ultra-fast all-optical operation, low latency, and scalability through cascade-ability.

*ivan.glesk@strath.ac.uk; phone 44141 548-2529; strath.ac.uk 


\section{TOWARDS ULTRAFAST ALL-OPTICAL DEVICES SUPPORTING OCDMA}

Having in mind the targeted high scalability for OCDMA systems, first we need to start with the selection of coding scheme such OCDMA systems will be using [6] in order to achieve the targeted performance. Improperly selected codes will affect cardinality, network scalability, achievable BER, and will increase Multi Access Interference (MAI). For these reasons, due to its unique properties, the 2D-WH/TS coding scheme is often selected to deliver the desired system performance and scalability of incoherent OCDMA [5]. However, to build these high performance systems based on 2DWH/TS OCDMA requires ultra-fast all-optical switching devices for time-gating, demultiplexing, and clock recovery but also requires high performance 'passive' all-optical devices such as Array Waveguide Gratings (AWGs), integrated optical filters and delay lines.

\subsection{All-optical ultra-fast switching devices for signal processing}

To overcome existing bottleneck imposed on signal processing due to limitations of the current electronics known as 'electronic bottle-neck', we need to develop ultra-fast all-optical switching devices. By the term 'all-optical' we understand that any signal (data) analog or digital being in optical form can be controlled (switched, sampled, demultiplexed, routed, thresholded) by the control signal also being in optical domain (i.e., optical clock, synchronization pulse, etc.).

In OCDMA applications, ultra-fast All-optical Asymmetric Demultiplexer (TOAD) [7] was used as ultra-fast all-optical $2 \mathrm{ps}$ time gate for removal/suppression of MAI [8]. The limitation of the TOAD device based on the optical semiconductor amplifier (SOA) is an SOA's relatively slow recovery time (5 ps or more). However, thanks to the SOA asymmetric configuration within of the Sagnac interferometer [7] this limitation is mitigated if the SOA based TOAD is used only as an ultra-fast all-optical demultiplexing gate but not as an 'AND' gate. To fully overcome this inconvenience, the exploited nonlinearity of the SOA can be replaced by the ultra-fast nonlinearity observed in the silicon nanowire waveguide. Using this approach, both interferometric switching configurations, Sagnac [10] as well as Mach-Zehnder [9] were successfully demonstrated. Using the above approach a picosecond time gating, ultrafast alloptical thresholding (including all-optical clock recovery) were successfully demonstrated $[8,9,10,12,13]$.

\subsection{SWG based Optical Filters, AWGs and delay lines for OCDMA applications}

Integrated optical filters, AWGs and delay lines belong to a category of key passive components which have a wide range of applications in optical communications including OCDMA. The AWGs are essential in constructing OCDMA encoders and decoders [1,2] including 2D-WH/TS code generations [3]. Optical filters are needed for optical clock suppression or extraction during all-optical signal processing during time gaiting or thresholding [5, 8, 9]. Recent advancements in the development of CMOS compatible approaches led to the development of devices based on siliconon insulator (SOI) as well as deployment of sub-wavelength waveguide gratings (SWG) technology $[14,17,18,19,20$, $21,22,23,24,25,26]$. All these helped with further device miniaturization and offered unique building blocks for future photonic devices. For example, since the effective index of the SWG waveguide is modifiable by selecting different 'block sizes and duty cycles', the properties of these devices could be greatly extended and controlled in order to deliver targeted parameters. This introduces a flexibility into controlling optical properties of the waveguide itself, including its refractive index, mode size, dispersion. Using these novel approaches, subwavelength waveguide gratings filtering devices and delay lines $[10,11,15]$ were demonstrated offering better compactness and support for bandwidth flexibility. All these new technological advancements could serve as a fundamental 'blocks' towards the development of novel high performance photonic integrated circuits to enable new ways in optical and microwave photonics signal processing functionalities.

\section{CONCLUSION}

We have discussed a need for highly scalable networks which can support a large number of simultaneous users in a growing presence of an electronic bottleneck. We have shown that a hybrid solutions involving incoherent Optical CDMA based on two-dimensional wavelength-hopping time-spreading codes when supported by ultra-fast all-optical signal processing can be an approach to meet the ever increasing demands in the fiber optic domain in the last mile solution or optical interconnects. To achieve these goals, the development of CMOS compatible all-optical devices is critical. We have indicated that the variety of all-optical signal processing devices, including those capable of ultra-fast 
all optical operation, have already been developed and demonstrated. However more research and development is still needed towards advance photonic chips development.

\section{REFERENCES}

[1] Yoshima, S., Nakagawa, Nakagawa, N. J. and Kitayama, K., "10G-TDM-OCDMA-PON systems," Proc. 15th OECC 2010, 724-725 (2010).

[2] Zhou, L., Cheng, X., Yeo, Y. -K. and Ngoh, L. H., "Hybrid WDM-TDM PON architectures and DWBA algorithms," Proc. 5th Int. ICST CHINACOM 2010, 1-6 (2010).

[3] Glesk, I., Andonovic, I. and Prucnal P. R., "Design and demonstration of OCDMA system with superior scalability," Proc. of SPIE 7138, 71381P-1 (2008).

[4] Osadola, T. B., Siti, K. I., Glesk, I. and Kwong, W. C., "Network scaling using OCDMA over OTDM," IEEE Photon. Technol. Lett. 24(5), 395 (2012).

[5] Glesk, I., Osadola, T. B. and Kwong, W. C., "Towards higher scalability of hybrid optical CDMA network," Optical and Quantum Electronics 49(8), 267-271 (2017).

[6] Yang, G. -C. and Kwong W. C., "Prime Codes with Applications to CDMA Optical and Wireless Networks," Artech House, Boston, 12-150 (2002).

[7] Sokoloff, J. P., Prucnal, P. R., Glesk, I. and Kane, M. "A Terahertz Optical Asymmetric Demultiplexer (TOAD)," IEEE Photon. Technol. Lett. 5(7), 787-790 (1993).

[8] Glesk, I., Prucnal, P. R. and Andonovic, I., "Incoherent ultrafast OCDMA receiver design with 2 ps all-optical time gate to suppress multiple-access interference," IEEE J. Sel. Topics Quantum Electron. 14(3), 861-867 (2008).

[9] Glesk, I., Bock, P. J., Cheben, P., Schmid, J. H., Lapointe, J. and Janz, S., "All-optical switching using nonlinear subwavelength Mach-Zehnder on silicon," Opt. Express 19(15), 14031-14039 (2011).

[10] Chen, L. R., Wang, Z., Wang, J., Glesk, I. and Adams, R., "Recent advances in all-optical signal processing in silicon photonics," Proc. Asia Communications and Photonics Conference, Optical Society of America, Su3D-5 (2017).

[11] Wang, J., Glesk, I. and Chen, L. R., "Subwavelength grating filtering devices," Opt. Express 22(13), 1533515345 (2014).

[12] Kravtsov, K., Deng, Y. and Prucnal, P. R., "Self-clocked all-optical add/ drop multiplexer for asynchronous CDMA ring networks," IEEE J. Quantum Electron. 45(4), 396 - 401 (2009).

[13] Idris, S. K., Osadola, T. B. and Glesk, I., "OCDMA receiver with built-in all-optical clock recovery," Electron. Lett. 49(2), 143-144 (2013).

[14] Janz, S., Cheben, P., Dalacu, D., Delge, A., Densmore, A., Lamontagne, B., Picard, M. J., Post, E., Schmid, J. H., Waldron, P., Xu, D. X., Yap, K. P., Ye, W. N., "Microphotonic elements for integration on the silicon-oninsulator waveguide platform," IEEE J. Sel. Topics Quantum Electron. 12(6), 1402-1415 (2006).

[15] Junjia, W., Glesk, I. and Chen, L. R. "Subwavelength grating devices in silicon photonics," Science Bulletin 61(11), 879-888 (2016).

[16]Ji, C., Broeke, R. G., Du, Y., Cao, J., Chubun, N., Bjeletich, P., Olsson, F., Lourdudoss, S., Welty, R., Reinhardt, C. and Stephan, P. L., "Monolithically integrated InP-based photonic chip development for OCDMA systems," IEEE J. Sel. Topics Quantum Electron. 11(1), 66-77 (2005).

[17] Cheben, P., Xu, D. X., Janz, S. and Delâge, A., "Scaling down photonic waveguide devices on the SOI platform," Proc. of SPIE 5117, 147-156 (2003).

[18] Cheben, P., [Wavelength dispersive planar waveguide devices: echelle and arrayed waveguide gratings], Optical Waveguides: From Theory to Applied Technologies, M. L. Calvo and V. Lakshminarayanan, Eds., chapter 5, CRC Press, London, UK (2007).

[19] Cheben, P., Janz, S., Xu, D. X., Lamontagne, B., Delâge, A. and Tanev, S., "A broad-band waveguide grating coupler with a subwavelength grating mirror," IEEE Photon. Technol. Lett. 18(1), 13-15 (2006).

[20] Cheben, P., Xu, D. X., Janz, S. and Densmore, A., "Subwavelength waveguide grating for mode conversion and light coupling in integrated optics," Opt. Express 14(11), 4695-4702 (2006). 
[21]Halir, R., Cheben, P., Janz, S., Xu, D. X., Molina-Fernández, Í. and Wangüemert-Pérez, J. G., "Waveguide grating coupler with subwavelength microstructures," Optics Lett. 34(9), 1408-1410 (2009).

[22] Bock, P. J., Cheben, P., Schmid, J. H., Lapointe, J., Delâge, A., Janz, S., Aers, G. C., Xu, D. X., Densmore, A. and Hall, T. J., "Subwavelength grating periodic structures in silicon-on-insulator: a new type of microphotonic waveguide," Opt. Express 18(19), 20251-20262 (2010).

[23] Cheben, P., Bock, P. J., Schmid, J. H., Lapointe, J., Janz, S., Xu, D. X., Densmore, A., Delâge, A., Lamontagne, B. and Hall, T. J., "Refractive index engineering with subwavelength gratings for efficient microphotonic couplers and planar waveguide multiplexers," Optics Lett. 35(15), 2526-2528(2010).

[24] Schmid, J. H., Cheben, P., Janz, S., Lapointe, J., Post, E. and Xu, D. X., "Gradient-index antireflective subwavelength structures for planar waveguide facets," Optics Lett. 32(13), 1794-1796 (2007).

[25] Wang, B., Jiang, J. and Nordin, G. P., "Embedded slanted grating for vertical coupling between fibers and silicon-on-insulator planar waveguides," IEEE Photon. Technol. Lett. 17(9), 1884-1886 (2005).

[26] Schmid, J. H., Cheben, P., Janz, S., Lapointe, J., Post, E., Delâge, A., Densmore, A., Lamontagne, B., Waldron, $\mathrm{P}$. and Xu, D. X., "Subwavelength grating structures in silicon-on-insulator waveguides," Advances in Optical Technologies, 2008, 1-8 (2008). 